\title{
Surviving the COVID - 19 Pandemic Resurgence: Not Easy but Achievable
}

\author{
Nomikos IN
}

\section{Introduction}

With the resurgence of the COVID-19 pandemic across the global and as the infected population is raised, our societal vigilance on protective measures (physical distancing, wearing masks and personal protection) should be strengthened, while waiting for the availability of safe and effective vaccines as well as other preventative and therapeutic measures.

Concerns about the growing number and severity of COVID-19 cases, the effects on the economy, and other stressors that we have experienced throughout the pandemic are reemerging. Surgeons continue to care for COVID-19 patients, while also handling surgical patient care as well as leading hospital activities to responding to COVID-19.

We have to face a variety of issues related to the harmful consequences of the crisis we experience. As a result, many of us may be feeling overwhelmed at this time. For practical reasons, I have divided these challenges into three categories. The first contains quality issues related to our mental health ((first category-resilience, well-being) that empower our efforts for providing medical care for COVID -19 patients, while also handling surgical patient care (second category-clinical issues). Providing surgical education to students, residents and fellows is another area of concern (third category-education), where collaborative efforts of institutions and clinical educators have resulted in big progress during this novel time.

\section{The Threat of our Mental Health}

As surgeons, we are known for our emotional resilience in the workplace and stamina. However, the COVID-19 pandemic resurgence comes with a new set of standards. The pressure of caring for patients is amplified in the setting of a virus with an explosive human-to-human transmission potential and no specific lifesaving treatment [1]. Handling life and death situations while simultaneously putting one's own life at risk contributes to an actual sense of danger. Triaging patients while knowing that there are a limited number of ventilators and ICU beds increase

Corresponding author: Iakovos N Nomikos MD FACS,

55 Psarron St., 18120 Koridallos, Piraeus Greece

e-mail: nomikosj@otenet.gr

Received Dec 3, 2020; Accepted Dec 7, 2020 emotional and psychological stress [2,3]. We must make critical decisions for our patients in the absence of family members since visitors are no longer allowed in hospitals. The emotional trauma endured by physicians is intensifying as we witness high volumes of death, including infection and deterioration of our colleagues and other health care providers [1].

Supporting our mental well-being and resilience is imperative to ensure global recovery from the COVID-19 pandemic. By establishing a hierarchy of needs will help to alleviate our psychological burden.

Psychological support should be made available in a variety of methods so that the physician has the freedom to choose an approach that works best. Emphasis should be placed on individualized emotional support plans as psychological care is not one-size-fits-all. This includes the use of telemedicine, video chats, or online forums $[1,4,5]$.

\section{How we learn to become resilient}

At this point, we need to reframe resilience away from the concept "I can shoulder it all," to: "I ask for assistance when I need it." Resilient people work through issues with other people.

An interesting concept of resilience starts with an observation: all of us possess the same fundamental stressresponse system, which has evolved over millions of years and which we share with others. The vast majority of people are quite good at using that system to deal with stress. When it comes to resilience, the question is: Why do some people use the system so much more frequently or effectively than others. It seems that in cases of positive reaction, the basic component of resilience is perception.

According to clinical psychology, we need to conceptualize a traumatic event as an opportunity to learn and become more informed. Events are not traumatic until we experience them as traumatic, and we might call them with an alternative and possibly more accurate term as potentially traumatic events (PTE). According to this concept, every frightening event, no matter how negative it might seem, it has the potential to be traumatic or not to the person experiencing it. If you take something as terrible as for example the unexpected death of a close friend you might be sad, but if you can find a way to build on that event and fill it with thoughts and meaning-perhaps that will lead to greater awareness of a certain disease or to closer ties with 
the community. In this case, this event may not be seen as a trauma. The experience is not inherent in the event; it resides in the event's psychological structure [6].

\section{Well-being}

\section{Managing ourselves. The Restorative Power of Rituals}

The trauma of COVID-19 is having immediate effects on people's emotional and physical health. Taking care of our mental health is not a luxury. From sadness, hopelessness, depression and panic to breathlessness, chest tightness and sleep disturbance, our bodies and minds are on high alert and exhausted at the same time. And when we feel this threat invading our lives, behaviours such as self-medication, substance abuse and self-harm, are on the way as well.

Rituals is an option to defend all these harmful consequences. Rituals can be recruited as a defensive mechanism as they play a number of critical roles: rituals in the face of loss can help us feel less grief, rituals with families can make us feel closer to each other, and rituals with our partners can reinforce our commitment to each other. The majority of people's rituals are private and idiosyncratic to them. At this current time, when we are all facing both actual and anticipated grief, these idiosyncratic rituals can restore our sense of control over our lives. We feel out of control when we experience loss - we didn't want it to happen, but we could not control it. Rituals restore some of that control.

It is not the repetition that makes a ritual, a real ritual. When we repeat rituals, they do seem to gain in strength, but even rituals performed a single time can be effective as one-time event. Many things we do every day are a little ritualistic. We may get ready for work the same way every morning - we might brush our teeth first and then shower. If we ask people to change the order and then report how they feel, some people do not care, but others mention that they feel a little uncomfortable. For the latter, their morning routine has become more of a ritual - it matters to them the order in which it happens, and when they do it "on their way" they feel happy and relaxed for the rest of the day. For many people there are rituals within the exercise as well, the routine. They walk at same time every day; they take the same route. Again, this all gives us that sense of control and it helps reduce anxiety and stress.

However, we need to be careful. By recruiting too many rituals, they may start to interfere with our day in a way that they force us to express an obsessive and compulsive behavior [7].

\section{Clinical Issues}

The COVID-19 pandemic has inflicted unprecedented stresses upon healthcare institutions and the caregivers who provide the front-line services needed to maximize the chances of survival and return to normalcy for patients who are infected and develop clinical symptoms.

Globally, the medical community through the different scientific organizations provides continuously, timely and appropriate instructions and guidelines to health care providers. Among them, the American College of Surgeons believes that a consistent policy protects essential medical services including surgery.

\section{Surgeons for In-of-Specialty Patient Care}

Now, everyone can trace published and updated recommendations for maintaining surgical services and for adjusting up or down depending upon a number of important considerations [8]. These recommendations include Regional Cooperation, supply chain flow, including the availability of PPE, COVID-19 testing, case prioritization, and various specific issues for perioperative care of COVID-19 patients. Appropriate tools such as the MeNTS (Medically necessary time sensitive procedures) scoring system provide institutions a useful framework to effectively and ethically triage patients for surgical care, while taking into account local case incidence, hospital capacity, PPE, and other factors. Certain circumstances allow surgical services to continue with appropriate planning and decision making [9].

Decisions to adjust surgical services up or down should be taken by hospital leaders including surgeons and in consultation with regional and/or national government leaders. The decisions should be based on local case incidence, ongoing testing of staff and patients, aggressive use of appropriate PPE and physical distancing practices. Local selection of cases performed should be based on urgency of patient needs, staff availability, and hospital bed capacity, but not by established and timely inappropriate guidelines. Surgical capacity can be safely maintained by following these recommendations, and will also prevent excessive backlogging of cases, which could cause treatment delays for patients who need surgical care. A multidisciplinary team should oversee guidelines for delivery of surgical services at each hospital according to the most recently updated instructions [10].

\section{Deployment of Surgeons for Out-of-Specialty Patient Care}

Deployment of surgeons to work outside of their usual specialty in order to maximize the effectiveness of available clinicians is always an option based on the experience of surgeons involved in the care of patients with COVID-19 infection. 
It is clear that the solutions chosen for individual COVID-19 units will need to be based on patient needs, availability of trained critical care surgeons, residents, physician assistants, advanced practice nurses and medical students. Once the needs of individual COVID - 19 patient care units have been assessed, deployment of surgeons to provide out-of-specialty care can be determined.

A team-based approach is a familiar way of providing surgical critical care. Integration of out-of-specialty surgeons into these teams can be used as needed when these resources are available. Team leaders, younger surgeons, and residents with recent critical care experience can supervise procedures and provide instructions for older general surgeons and out-of-specialty surgeons.

Feedback from nursing and respiratory therapy staff has been recognized as a valuable resource in these areas. Team meetings at the beginning and at the end of shifts provide hand-off and teaching. Team leaders are encouraged to "lead from the rear" to minimize the risk of infection of experienced clinicians. Available teaching resources is provided to team members. This approach has worked well in the institutions where it was applied $[11,12]$.

\section{Military and Civilian Health Systems Partnership}

Another potentially helpful option is a military and civilian health systems partnership. It's clear that the existing hospital infrastructure in many countries is insufficient to deal with the potential number of patients, particularly individuals who require intensive care and ventilator support. The civilian hospital infrastructure will need to develop creative methods to manage these patients, as well as the patients who are already in hospitals.

Portable military facilities staffed with military and civilian medical personnel could make available staff, beds and equipment in those civilian hospitals for the care of victims of COVID-19.

For a such a successful partnership, criteria outlined by the American College of Surgeons (ACS) can be found in the "Blue Book". This book provides guidance on important topics such as institutional commitment, administration, human resources, physical resources, education, and evaluation [13].

The "Blue Book" was created under the aegis of the Military Health System Surgery Partnership American College of Surgeons (MHSSPACS), established in 2014 as collaborative effort between the College and the US Department of Defense. The MHSSPACS has developed the criteria for the selection and evaluation of military civilian partnerships to effectively provide the training needed. Although, the "Blue Book", is designed for military readiness, it can be easily adapted for the collaboration of civilian and military teams in response to any disaster, including the COVID-19 pandemic [13].

\section{The New Face of Medical Education}

With pandemic-induced major interruption of medical education at all levels, in March of 2020, medical schools worldwide managed medical education without in-person clinical experiences, and, at the same time, they developed plans and curricula including virtual education for the unpredictable future. Although education through digital resources is not enough, curricula and learning objectives should be revised and adapted to the new reality.

Clinical education has historically been dominated by on-site experiences in clinics, hospital wards and operating rooms. There has been a tremendous effort to develop teaching methods and tools making use of ever-increasing technological advancement. A review of medical literature over the last fifteen years demonstrates a wide variety of tools developed and studied, from 'home-grown' e-learning modules [14-18] to proprietary internet accessible computer aided learning systems [19-24]. These materials include both medical knowledge and clinical decision-making concepts that often take the form of case studies, many of which are interactive. Even more materials, such as podcasts [25] and open-access platforms $[26,27]$ have been studied, often in comparison to traditional textbook learning or face-to-face lecturing $[28,29]$.

There is clear evidence to support that electronic learning modalities can offer equivalent or even superior results than 'traditional' methods, and that students appear to find many of these experiences satisfactory, sometimes rating them more favorably than textbook learning or lecture experiences $[14,15,18,19,24,25]$. All these different options must be considered within the learning objectives set by the medical schools.

Efforts to utilize electronic learning, both synchronous and asynchronous, have allowed for some programs to have a relatively seamless progression of clinical medical education during the Covid-19 pandemic. While many of these tools were designed to supplement clinical education, now they are evaluated in a new perspective, with the potential of using such a tools and methods even more to the upfront of clinical medical education in surgery and beyond.

In the future, many forms of virtual education may stay if they are considered to be better than traditional teaching. It is also worth mentioning that the highest studied electronic learning in medical education, thus far, has been of asynchronous format, whereas at the same time, it appears that there is a fair amount of synchronous virtual teaching taking place during this novel period. 


\section{References}

1. Huang J, Liu F, Teng Z, et al. Care for the psychological status of frontline medical staff fighting against COVID-19. Oxford University Press for the Infectious Diseases Society of America; 2020.

2. SenniM. COVID-19 experience in Bergamo, Italy. Eur Heart J 2020;41:1783-4.

3. Clark AL, Stephens AF, Liao S, et al. Coping with COVID-19: ventilator splitting with differential driving pressure using standard hospital equipment. Anaesthesia 2020;75:872-80.

4. Santarone Kristen, McKenney M, Elkbuli A. Preserving mental health and resilience in frontline healthcare workers during COVID-19 (Correspondence) Am J Emerg Med [Internet] 2020;38:1530-1. Available from: https://doi.org/10.1016/j. ajem.2020.04.030

5. Lai J, Ma S, Wang Y, et al. Factors associated with mental health outcomes among health care workers exposed to coronavirus disease 2019. JAMA Netw Open [Internet] 2020;3:e203976. Available from: https://www.ncbi.nlm.nih. gov/pmc/articles/PMC7090843/

6. Konnikova M. How People learn to become resilient. The New Yorker 2016;Feb 16. Available from: https://www.newyorker.com/science/maria-konnikova/the-secret-formulafor-resilience

7. Scott Bennato. The restorative power of ritual. Harvard Business Review 2020;April 02. Available from: https:// hbr.org/2020/04/the-restorative-power-of-ritual?ab=heromain-text

8. Joint Statement: Roadmap for Maintaining Essential Surgery during COVID-19 Pandemic. [Internet] 2020;Nov 23. Available from: https://www.facs.org/covid-19/clinical-guidance/ nov2020-roadmap

9. Prachand VN, Milner R, Angelos P, et al. Medically necessary, time-sensitive procedures: Scoring system to ethically and efficiently manage resource scarcity and provider risk during the COVID-19 Pandemic. J Am Coll Surg 2020;231:281-8. Doi: 10.1016/j.jamcollsurg.2020.04.01

10. ACS. COVID-19. Guidance for triage of non emergent surgical procedures. American College of Surgeons [Internet] 2020;March. Available from: https://www.facs.org/covid-19/ clinical-guidance/triage

11. ACS. Covid-19 and Surgery. Deployment of surgeons for out-of-specialty patient care. American College of Surgeons [Internet] 2020 March. Available from: https://www.facs.org/ covid-19/clinical-guidance/workforce-deployment

12. University of Pennsylvania. Suggested Health Care System Response to Needs for Personnel Deployment during the COVID19 Pandemic: ideas from the University of Pennsylvania http://www.facs.org/ /media/Files/COVID19/ Penn_Medicine_Workforce_Redeployment.ashx

13. ACS. The Blue Book: Military-civilian partnerships for trauma training, sustainment, and readiness. Chicago: American College of Surgeons; 2020. Available from: https://www.facs. org/covid-19/clinical-guidance/blue-book
14. Egro FM, Tayler-Grint LC, Vangala SK, et al. Multicenter Randomized Controlled Trial to Assess an e-Learning on Acute Burns Management. J Burn Care Res 2018;39:94-9.

15. Corrigan M, Reardon M, Shields C, et al. "SURGENT" -student e-learning for reality: The application of interactive visual images to problem-based learning in undergraduate surgery. J Surg Educ 2008;65:120-5.

16. Stahl A, Boeker M, Ehlken C, et al. Evaluation of an internetbased e-learning ophthalmology module for medical students. Ophthalmologe. 2009;106:999-1005.

17. Amendola MF, Bosch G, Kaplan B. Talking about ethical issues in surgery-results of a novel online pilot curriculum. J Surg Educ 2019;76:1562-8.

18. Al-Hussaini A, Tomkinson A. Exploring medical undergraduates' perceptions of the educational value of a novel ENT iBook: A Qualitative Study. J Vis Commun Med 2016;39:3-9.

19. Subramanian A, Timberlake M, Mittakanti H, et al. Novel educational approach for medical students: Improved retention rates using interactive medical software compared with traditional lecture-based format. J Surg Educ 2012; 69:253-6.

20. Healy DG, Fleming FJ, Gilhooley D, et al. Electronic learning can facilitate student performance in undergraduate surgical education: A prospective observational study. BMC Med Educ 2005;5:23.

21. Leonardo Oliveira Reis, Osamu Ikari, Khaled A Taha-Neto, et al. Delivery of a urology online course using moodle versus didactic lectures methods. Int J Med Inform 2015; 84:149-54.

22. Schneider AT, Albers P, Müller-Mattheis V. Learning in Urology: Implementation of the learning and teaching platform CASUS ${ }^{\varpi}$ - Do virtual patients lead to improved learning outcomes? A Randomized Study among Students. Urol Int 2015;94:412-8.

23. Phitayakorn R, Nick MW, Alseidi A, et al. WISE-MD Usage among millennial medical students. Am J Surg 2015; 209:152-7.

24. Horstmann M, Renninger M, Hennenlotter J, et al. Blended E-learning in a Web-based virtual hospital: A useful tool for undergraduate education in urology. Educ Health (Abingdon). 2009;22:269.

25. David Alexander Back, Jennifer von Malotky, et al. Superior gain in knowledge by podcasts versus text-based learning in teaching orthopedics: A Randomized Controlled Trial. J Surg Educ 2017;74:154-60.

26. Moreau JJ, Caire F, Kalamarides M, et al. Changing the teaching of neurosurgery with information technology. Presse Med 2009;38:1425-33.

27. Wierlemann A, Seyfried F, Thomas C. Multimedia e-learning in surgery, 10 years experience at the university of Würzburg. Germer Zentralbl Chir 2019;144:560-72.

28. Benditz A, Pulido L, Renkawitz T, et al. Are there gender-dependent study habits of medical students in times of the world wide web? Biomed Res Int [Internet] 2018;2018:3196869. Doi: 10.1155/2018/3196869. eCollection 2018

29. Tarpada SP, Morris MT, Burton DA. E-learning in orthopedic surgery training: A systematic review. J Orthop 2016;13:42530. 